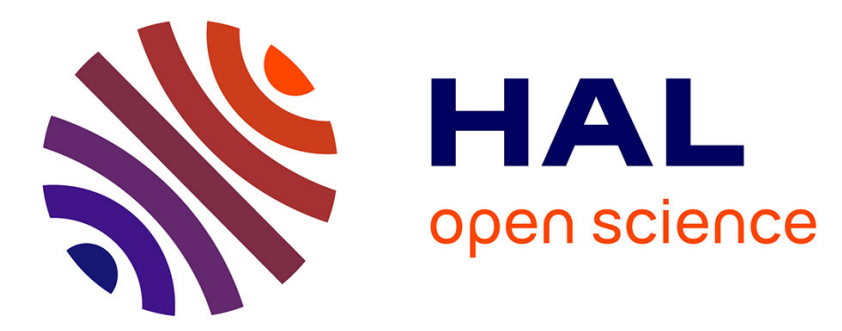

\title{
Effects of e-mails containing ADR information and a current case report on ADR reporting rate and quality of reports
}

Marie-Louise Johansson, Gertrud Brunlöf, Christina Edward, Susanna M. Wallerstedt

\section{To cite this version:}

Marie-Louise Johansson, Gertrud Brunlöf, Christina Edward, Susanna M. Wallerstedt. Effects of emails containing ADR information and a current case report on ADR reporting rate and quality of reports. European Journal of Clinical Pharmacology, 2009, 65 (5), pp.511-514. 10.1007/s00228-0080603-6 . hal-00534937

\section{HAL Id: hal-00534937 \\ https://hal.science/hal-00534937}

Submitted on 11 Nov 2010

HAL is a multi-disciplinary open access archive for the deposit and dissemination of scientific research documents, whether they are published or not. The documents may come from teaching and research institutions in France or abroad, or from public or private research centers.
L'archive ouverte pluridisciplinaire $\mathbf{H A L}$, est destinée au dépôt et à la diffusion de documents scientifiques de niveau recherche, publiés ou non, émanant des établissements d'enseignement et de recherche français ou étrangers, des laboratoires publics ou privés. 


\title{
Effects of e-mails containing ADR information and a current case report on ADR reporting rate and quality of reports
}

\author{
Marie-Louise Johansson • Gertrud Brunlöf • \\ Christina Edward • Susanna M. Wallerstedt
}

Received: 28 August 2008 / Accepted: 5 December 2008 /Published online: 7 January 2009

(C) Springer-Verlag 2008

\begin{abstract}
Background Spontaneous reporting of adverse drug reactions (ADRs) is one approach to increasing our knowledge on the risks of drugs in clinical practice. Under-reporting is a shortcoming of this system.

Objectives To evaluate if repeated e-mails with attachments on ADR information can affect (1) the reporting of ADRs and (2) the quality of the ADR reports.

Methods All 117 heads of primary health care units in the region of Västra Götaland in Sweden were randomly allocated (1:1) to an intervention group or a control group. The intervention consisted of e-mails with attachments sent out to each of the 117 heads in January, May and September 2007. These e-mails included (1) the heading "Every ADR report is important", (2) a current case report of an ADR and (3) instructions on how to report. The number of reports from each primary health care unit run by the same head was registered, as was the quality of the report. The quality was defined as high if the ADR was (1) serious, (2) unexpected or (3) related to the use of new drugs and not labeled as common in the summary of product characteristics. All other reports were regarded as low-quality reports.

Results The total number of reports increased from 89 in 2006 to 111 in $2007(P=0.037)$. No difference in the
\end{abstract}

\footnotetext{
M.-L. Johansson • G. Brunlöf · S. M. Wallerstedt $(\triangle)$

Department of Clinical Pharmacology and Regional

Pharmacovigilance Center, Sahlgrenska University Hospital,

41345 Göteborg, Sweden

e-mail: susanna.wallerstedt@pharm.gu.se

C. Edward

Department of Health, Pharmaceutical Unit, Regionens Hus, 41345 Göteborg, Sweden
}

number of reports between intervention $(n=56)$ and control $(n=55)$ units could be detected. The proportion of highquality reports before and after the intervention was 36 and $48 \%$, respectively (intervention, $P=0.11$ ) and 40 and $36 \%$, respectively (control, $P=0.55$ ).

Conclusions No apparent effect of repeated ADR e-mails on the reporting of ADRs could be detected, although an increase in the reporting rate in general was noted.

Keywords Adverse drug reaction · Quality of reports . Reporting rate

\section{Introduction}

Adverse drug reactions (ADRs) are a major health care problem and a common cause for hospital care [1-3]. Consequently, an analysis of risks and benefits is essential before initializing drug treatment in patients. Such an analysis, however, implies access to adequate knowledge on these parameters. After a drug is registered, a large number of patients with characteristics often widely differing from those in the preregistration studies are exposed to the drug, such as elderly patients, nonadherent patients and patients with concomitant diseases treated with other drugs (polypharmacy). The drug safety information is limited for these patient groups, and post-marketing surveillance is therefore an important tool for increasing our knowledge of risk and benefits of drugs.

Spontaneous reporting of ADRs is one approach by which the knowledge of the risks of a drug in clinical practice can be increased. It is an important method for detecting signals, which is one aim of pharmacovigilance. In Sweden, authorized prescribing health care providers (physicians, dentists) and nurses are obliged to report (1) 
serious ADRs, (2) ADRs not mentioned in the summary of product characteristics (SPC), (3) ADRs related to the use of new drugs ( $\leq 2$ years on the market) except those labeled as common in the SPC and (4) ADRs whose incidence seems to increase [4], the latter obviously being difficult for any individual to identify. All ADR reports are reviewed by trained nurses (MLJ, GB) and clinical pharmacologists (SMW) at regional pharmacovigilance centers, after which they are entered in the SWEdish Drug Information System (SWEDIS). The ADR reports are assessed in terms of causality and seriousness according to World Health Organization (WHO) criteria.

A serious drawback of the spontaneous reporting system is that only a small proportion of all ADRs are reported $[5,6]$. Low reporting rates may be due to the lack of time and/or lack of knowledge on how to report them [7] as well as attitudes, such as the belief that (1) ADRs are well documented by the time a drug is marketed, (2) one should only report an ADR if there is no doubt that it is related to the utilized drug or (3) the single case any individual doctor may see could not contribute to medical knowledge [8,9].

Methods that are known to increase ADR reporting include (1) education [10,11], (2) access to report forms in combination with verbal reminders [12] and (3) distribution of a drug-safety bulletin [13] and detailed drug-specific feedback to the reporting doctor [14]. Some of these methods are time-consuming and therefore costly. Moreover, for all the methods mentioned, the effects may diminish over time. Consequently, there is an urgent need for an easily managed, but continuously up-dated method (=on-going) aimed at improving ADR reporting without too much effort or cost.

In the region of Västra Götaland in Sweden, there are 123 primary health care units directed by 117 heads. News concerning drugs is distributed via attachments in e-mails to the heads of the primary health care units, who are instructed to forward the message to their employees. The "e-mail attachment" system has been used since 2005, and approximately 25 e-mails are distributed each year. This system has been shown to influence sales of prescribed drugs, indicating that the e-mails are read by primary care doctors and considered to these individuals to be trustworthy [15].

The aim of the study reported here was to evaluate whether repeated e-mails with attachments containing ADR information can affect (1) the reporting of ADRs and (2) the quality of the ADR reports.

\section{Methods}

The 117 heads of primary health care units in the region of Västra Götaland were randomly allocated in a 1:1 fashion to an intervention group or a control group. It was expected that each unit reported ADRs to varying extents. In addition, a small number of the units were participating in a contemporary educational intervention during the study period. Consequently, the allocation was stratified according to number of ADR reports in 2006 and whether or not the unit had received the educational intervention. A person not involved in the study and without any knowledge of the study protocol performed the randomization procedure.

The intervention consisted of repeated e-mails with attachments during 2007. These followed the established system for e-mails on drug news and included one page with (1) the heading "Every ADR report is important", (2) a current case report of an ADR and (3) instructions on how to report. The e-mails were distributed three times during 2007, in January, May and September, with each including a new current case report of an ADR.

The number of reports from each primary care unit run by the same head was registered, as was the quality of the report. The quality was defined as high if the ADR undoubtedly should have been reported, i.e. was (1) serious, (2) unexpected or (3) related to the use of new drugs and not labeled as common in the SPC. All other reports were regarded as low-quality reports.

\section{Statistics}

Statistical analyses were conducted using SPSS ver. 14.0 (SPSS, Chicago, IL). The Wilcoxon signed rank test was used for comparisons within groups, and the MannWhitney test was used for comparisons between groups. A $P$ value $<0.05$ was considered to be significant.

\section{Results}

Before the intervention (2006), a total of 89 reports from the primary health care units were registered, with the number of reports per unit ranging from zero to 12 (intervention group) and zero to five (control group). The

Table 1 Number and quality of reports in the primary health care units in 2007

\begin{tabular}{lll}
\hline Reports & $\begin{array}{l}\text { Intervention } \\
\text { units }(n=59)\end{array}$ & $\begin{array}{l}\text { Control } \\
\text { units }(n=58)\end{array}$ \\
\hline Total & 56 & 55 \\
Serious & $10(18)$ & $9(16)$ \\
Previously not known ADR & $16(29)$ & $11(20)$ \\
New drug & $4(7)$ & $1(2)$
\end{tabular}

ADR, Adverse drug reaction

Values are given as the number $(n)$ with the percentage in parenthesis 
proportion of high-quality reports did not differ between the groups -36 and $40 \%$ in the intervention and control group, respectively $(P=0.38)$.

The total number of reports increased to 111 in 2007 , which is a $25 \%$ increase in the number of reports per unit compared to 2006 ( $P=0.037$ ). Of these, 56 were in the intervention group (range zero to six reports per unit) and 55 were in the control group (range zero to eight reports per unit). The proportion of units reporting ADRs in $2007 \mathrm{did}$ not differ between the intervention and the control group (49 vs. $52 \%, P=0.78$ ). The proportion of high-quality reports before and after the intervention was 36 and $48 \%$, respectively, in the intervention group $(P=0.11)$ and 40 and $36 \%$, respectively, in the control group $(P=0.55)$. However, the proportion of high-quality reports did not differ between the groups $(P=0.53)$. The number and quality of reports are shown in Table 1.

In the intervention group, 16 reports concerned ADRs not mentioned in the SPC. The corresponding figure in the control group was 11. These reports are described in Table 2 .

\section{Discussion}

The number of ADR reports per primary health care unit increased from 2006 to 2007 . However, an isolated effect of the intervention could not be detected, since neither the number of reports nor the proportion of units reporting ADRs differed between the intervention and the control units. One explanation for the results of our study may be an increased attention to patient safety in general and, therefore, also a focus on ADR reporting. The intervention may also have spilled over to the control units. Doctors may work in more than one primary health care unit, i.e. both in the intervention group and in the control group. Also, the units all belong to the same organization, and information may easily be passed on from one unit to another. Also, given the available number of health care units in the region, the study had a power of $>80 \%$ to detect a doubling of the reporting in the intervention group. Thus, the results indicate that repeated e-mails may not affect the reporting rate to a major extent. Indeed, the intervention could be of importance even with a smaller effect, since it

Table 2 Description of ADRs not mentioned in the SPC reported by the primary health care units

\begin{tabular}{|c|c|c|c|c|c|c|}
\hline Randomization group ${ }^{\mathrm{a}}$ & Age (years) & Gender $^{\mathrm{b}}$ & ADR diagnosis/es & Suspected drug(s) & Serious & New drug \\
\hline I & 25 & $\mathrm{~F}$ & Leg pain & Mirtazapine & No & No \\
\hline I & 33 & $\mathrm{~F}$ & Hyperprolactinemia & Lithium & No & No \\
\hline I & 35 & M & Paraesthesia & Terbinafine & No & No \\
\hline I & 47 & $\mathrm{~F}$ & Syncope & Etoricoxib & No & No \\
\hline I & 49 & $\mathrm{~F}$ & Bradycardia, apathy & Varenicline & No & Yes \\
\hline I & 50 & $\mathrm{~F}$ & Nightmares & Loratadine & No & No \\
\hline I & 59 & $\mathrm{~F}$ & Photosensitivity & Buprenorphine & No & No \\
\hline I & 61 & M & Hyperpigmentation & Warfarin & No & No \\
\hline I & 65 & $\mathrm{~F}$ & Confusion & Nitrofurantoin & No & No \\
\hline I & 73 & $\mathrm{~F}$ & Taste alteration, parosmia & Amoxicillin & Yes & No \\
\hline I & 74 & M & Melaena & Ketoprofen & No & No \\
\hline I & 74 & $\mathrm{~F}$ & Syncope & Varenicline & Yes & Yes \\
\hline I & 79 & M & Erythema multiforme & Propiomazine, paracetamol, zopiclone & Yes & No \\
\hline I & 81 & M & Petechiae & Dexibuprofen, ketoprofen & Yes & No \\
\hline I & 81 & M & Prothrombin decreased & Warfarin, nabumetone & No & No \\
\hline I & 82 & $\mathrm{~F}$ & Nightmares & Simvastatin & No & No \\
\hline $\mathrm{C}$ & 29 & $\mathrm{~F}$ & Galactorrhea, nasal congestion & Citalopram & No & No \\
\hline $\mathrm{C}$ & 31 & $\mathrm{~F}$ & Palpitations & Ketoprofen & No & No \\
\hline $\mathrm{C}$ & 32 & M & Pulmonary embolism & Venlafaxine & Yes & No \\
\hline $\mathrm{C}$ & 36 & $\mathrm{~F}$ & Hemorrhage nos & Pregabalin & No & No \\
\hline $\mathrm{C}$ & 40 & $\mathrm{~F}$ & Vasodilatation & Amitriptyline & No & No \\
\hline $\mathrm{C}$ & 45 & $\mathrm{~F}$ & Skin discoloration & Hydroxocobalamin & No & No \\
\hline $\mathrm{C}$ & 47 & $\mathrm{~F}$ & Angioedema & Solifenacin & Yes & Yes \\
\hline $\mathrm{C}$ & 52 & $\mathrm{~F}$ & Rash pustular, psoriasis aggravated & Chloroquine phosphate & No & No \\
\hline $\mathrm{C}$ & 54 & $\mathrm{~F}$ & Chest pain & Ramipril & No & No \\
\hline $\mathrm{C}$ & 76 & $\mathrm{~F}$ & Insomnia & Simvastatin & No & No \\
\hline $\mathrm{C}$ & 82 & $\mathrm{~F}$ & Stomatitis & Codeine+ + paracetamol & No & No \\
\hline
\end{tabular}

SPC, Summary of product characteristics

${ }^{a} \mathrm{C}$, Control; I, intervention

${ }^{\mathrm{b}}$ F, Female; M, male 
is neither costly nor time-consuming. To investigate this possibility would require an expanded "e-mail attachment" system that includes more than the 117 heads of our region.

The number of high-quality reports increased numerically in the intervention group, but not in the control group. However, the power of the study to detect significant differences regarding this aspect was low. A previous study has shown that an educational program may increase the quality of the reports [10]. Further evaluation of a combination of an educational program and repeated e-mails for increased quality of reports may be of interest.

One major limitation of the study is that an individual doctor's interest in ADRs may have a great impact on the reporting rate; for example, a total of 12 reports were registered from one primary care unit, all of which came from the same doctor. Another limitation of the study is that we do not know whether the intervention actually reached the target population. However, the "e-mail attachment" system has been on-going for several years and has been shown to influence the sales of prescribed drugs, indicating that the system seems to be working properly [15]. On the other hand, heads of primary health care units could be more inclined to push their doctors to prescribe cost-effective drugs according to producerindependent drug information, thus improving the local budget of the unit, rather than to push their doctors to report ADRs, an action which does not directly benefit the unit, but is of worldwide interest for safe drug use.

In conclusion, no apparent effect of repeated ADR e-mails on the reporting of ADRs could be detected. However, an increase in the reporting rate in general was found.

Acknowledgments The authors are grateful to John Karlsson, Department of Clinical Pharmacology, for the randomization procedure. The study was supported by the Swedish Foundation for Strategic Research and The Swedish Society of Medicine.

Conflict of interest statement No conflicts of interests exist.

\section{References}

1. Mjorndal T, Boman MD, Hagg S et al (2002) Adverse drug reactions as a cause for admissions to a department of internal medicine. Pharmacoepidemiol Drug Saf 11:65-72

2. Schneeweiss S, Hasford J, Gottler M et al (2002) Admissions caused by adverse drug events to internal medicine and emergency departments in hospitals: a longitudinal populationbased study. Eur J Clin Pharmacol 58:285-291

3. van den Bemt PM, Egberts AC, Lenderink AW et al (1999) Adverse drug events in hospitalized patients. A comparison of doctors, nurses and patients as sources of reports. Eur J Clin Pharmacol 55:155-158

4. Medical Products Agency (2006) Code of statutes. Medical Products Agency, Uppsala

5. Alvarez-Requejo A, Carvajal A, Begaud B et al (1998) Underreporting of adverse drug reactions. Estimate based on a spontaneous reporting scheme and a sentinel system. Eur J Clin Pharmacol 54:483-488

6. Backstrom M, Mjorndal T, Dahlqvist R (2004) Under-reporting of serious adverse drug reactions in Sweden. Pharmacoepidemiol Drug Saf 13:483-487

7. Belton KJ (1997) Attitude survey of adverse drug-reaction reporting by health care professionals across the European Union. The European Pharmacovigilance Research Group. Eur J Clin Pharmacol 52:423-427

8. Backstrom M, Mjorndal T, Dahlqvist R et al (2000) Attitudes to reporting adverse drug reactions in northern Sweden. Eur J Clin Pharmacol 56:729-732

9. Herdeiro MT, Figueiras A, Polonia J et al (2005) Physicians' attitudes and adverse drug reaction reporting: a case-control study in Portugal. Drug Saf 28:825-833

10. Figueiras A, Herdeiro MT, Polonia J et al (2006) An educational intervention to improve physician reporting of adverse drug reactions: a cluster-randomized controlled trial. JAMA 296:10861093

11. Backstrom M, Ekman E, Mjorndal T (2007) Adverse drug reaction reporting by nurses in Sweden. Eur J Clin Pharmacol 63:613-618

12. McGettigan P, Golden J, Conroy RM et al (1997) Reporting of adverse drug reactions by hospital doctors and the response to intervention. Br J Clin Pharmacol 44:98-100

13. Castel JM, Figueras A, Pedros C et al (2003) Stimulating adverse drug reaction reporting: effect of a drug safety bulletin and of including yellow cards in prescription pads. Drug Saf 26:10491055

14. Wallerstedt SM, Brunlof G, Johansson ML et al (2007) Reporting of adverse drug reactions may be influenced by feedback to the reporting doctor. Eur J Clin Pharmacol 63:505-508

15. Edward C, Himmelmann A, Wallerstedt SM (2007) Influence of an e-mail with a drug information attachment on sales of prescribed drugs: a randomized controlled study. BMC Clin Pharmacol 7:12 